\title{
ALD $\mathrm{SnO}_{2}$ coated anodic $1 \mathrm{D} \mathrm{TiO}_{2}$ nanotube layers for low concentration $\mathrm{NO}_{2}$ sensing
}

Siowwoon Ng, ${ }^{\text {Jan }}$ Prášek, ${ }^{1}$ Raul Zazpe, ${ }^{1,2}$ Zdeněk Pytliček, ${ }^{1}$ Zdeněk Spotz,, Jhonatan Rodriguez Pereira, ${ }^{2}$ Jan Michalička, ${ }^{1}$ Jan Přikryl, ${ }^{2}$ Miloš $\mathrm{Krbal}^{2}$, Hanna Sopha ${ }^{1,2}$, Jaromír Hubálek , Jan M. Macák, ${ }^{1,2, *}$

${ }^{1}$ Central European Institute of Technology, Brno University of Technology, Purkyňova 123, 61200 Brno, Czech Republic.

${ }^{2}$ Center of Materials and Nanotechnologies, Faculty of Chemical Technology, University of Pardubice, Nám. Cs. Legií 565, 53002 Pardubice, Czech Republic.

*Corresponding author: Jan M. Macak (jan.macak@upce.cz) 


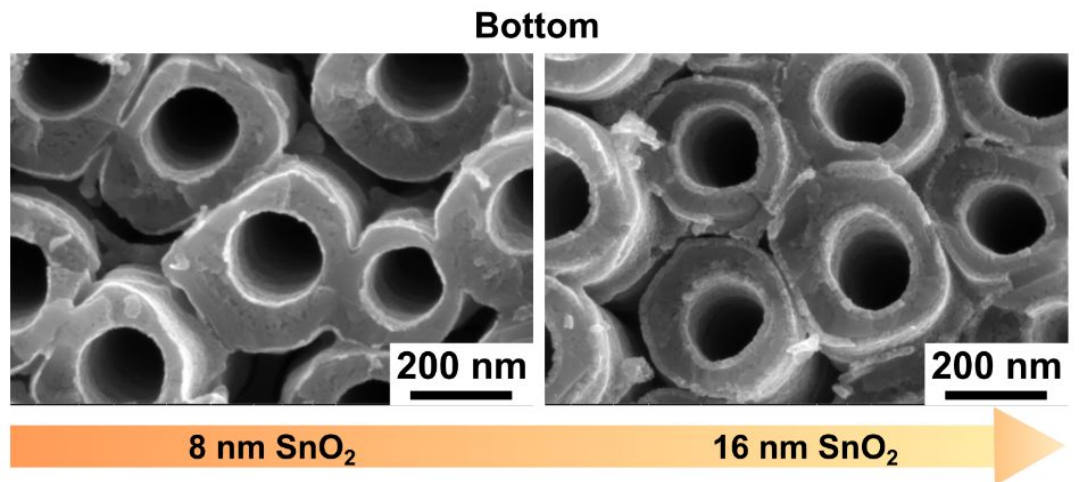

Figure S1 SEM images of $8 \mathrm{~nm}\left(\mathrm{~N}_{\mathrm{ALD}}=94\right)$, and $16 \mathrm{~nm}\left(\mathrm{~N}_{\mathrm{ALD}}=189\right) \mathrm{SnO}_{2}$ deposited $\mathrm{TiO}_{2}$ nanotube layers. Images were taken at the interface of the bottom part of $\mathrm{TiO}_{2}$ nanotube layers and $\mathrm{Ti}$ substrate, after all sensing measurements.

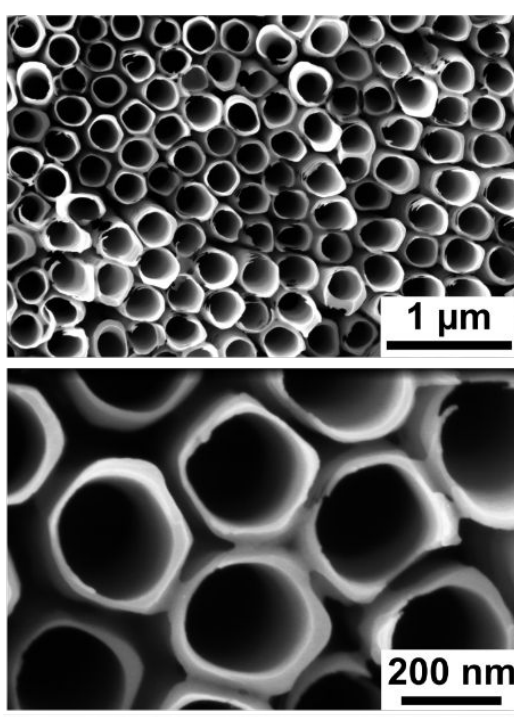

Blank

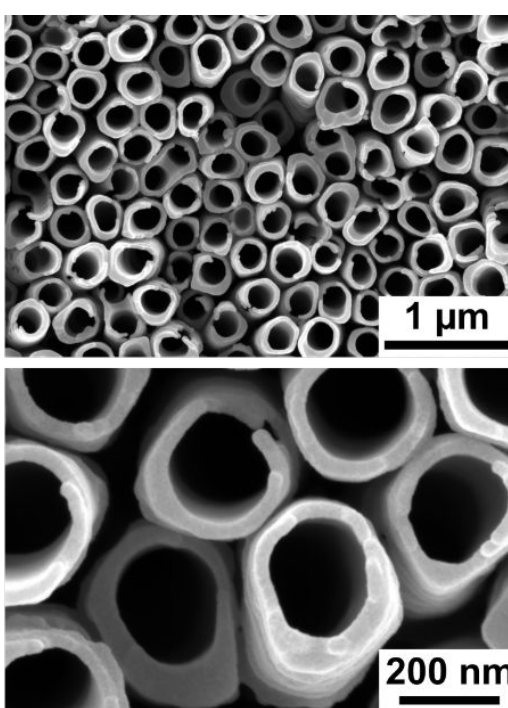

$8 \mathrm{~nm} \mathrm{SnO} 2$

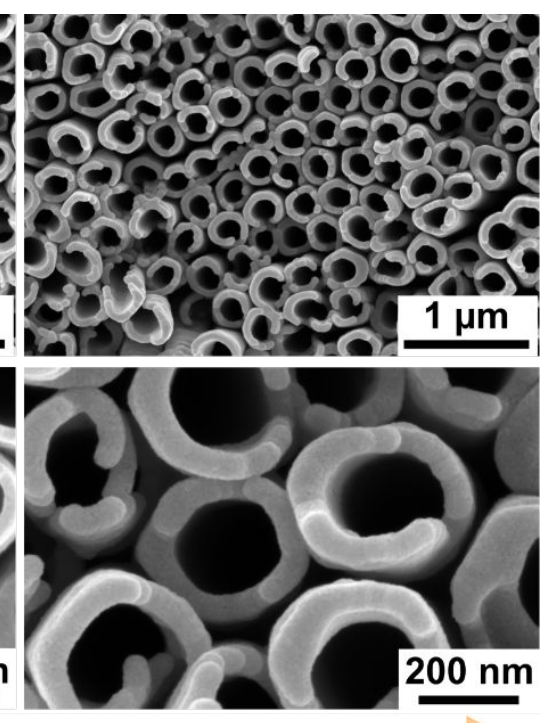

$16 \mathrm{~nm} \mathrm{SnO}{ }_{2}$

Figure S2 SEM images of blank, $8 \mathrm{~nm}\left(\mathrm{~N}_{\mathrm{ALD}}=94\right)$, and $16 \mathrm{~nm}\left(\mathrm{~N}_{\mathrm{ALD}}=189\right) \mathrm{SnO}_{2}$ deposited $\mathrm{TiO}_{2}$ nanotube layers after all sensing measurements. 


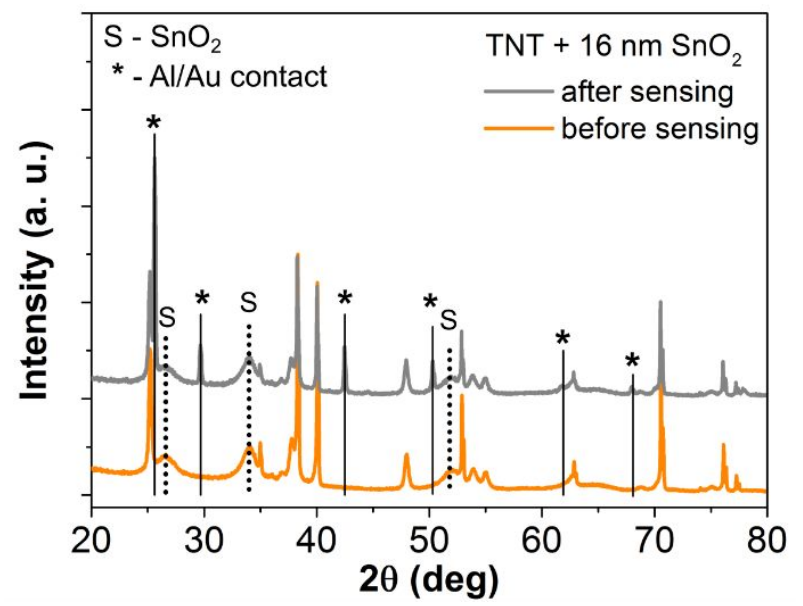

Figure $\mathrm{S} 3 \mathrm{XRD}$ patterns of $16 \mathrm{~nm}\left(\mathrm{~N}_{\mathrm{ALD}}=189\right) \mathrm{SnO}_{2}$ deposited $\mathrm{TiO}_{2}$ nanotube layers before and after sensing measurements.

For simplicity, only $\mathrm{SnO}_{2}$ and the additional $\mathrm{Al}_{2} \mathrm{Au}$ diffraction planes are marked in Figure $\mathrm{S} 3$. $\mathrm{Al}_{2} \mathrm{Au}$ are originated from the $\mathrm{Al}$ and $\mathrm{Au}$ electrical contacts for sensing measurements. The alloy is a consequence of Au diffusing into $\mathrm{Al}$ as the sensor was measured up to $300{ }^{\circ} \mathrm{C}$. The remaining peaks are $\mathrm{TiO}_{2}$ and $\mathrm{Ti}$. The comparison shows that no discernable change in $\mathrm{SnO}_{2}$ peaks, which strongly supports that the $\mathrm{SnO}_{2}$ deposited $\mathrm{TiO}_{2}$ nanotube layer is highly stable for long term sensing purpose.
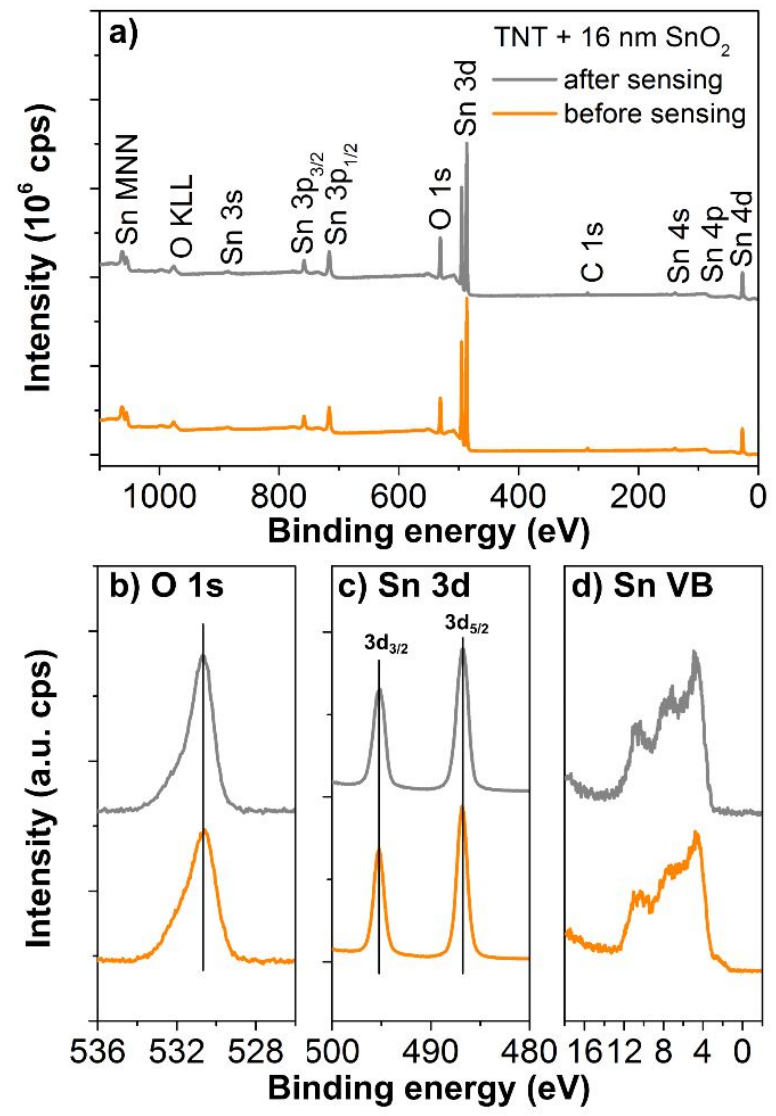

Figure S4 (a) XPS survey, (b) O 1s, (c) Sn 3d, and (d) Sn valence band (VB) spectra of $16 \mathrm{~nm}$ $\left(\mathrm{N}_{\mathrm{ALD}}=189\right) \mathrm{SnO}_{2}$ deposited $\mathrm{TiO}_{2}$ nanotube layers before and after sensing measurements. 